\title{
Lymphovascular Invasion 0
}

National Cancer Institute

\section{Source}

National Cancer Institute. Lymphovascular Invasion O. NCI Thesaurus. Code C147091.

Lymphovascular invasion is not present (absent) or is not identified. (AJCC 8th ed.) 